\title{
Effect of Rehabilitation Program for Wrist Joint affected with Ligaments Strain In Table Tennis players
}

\section{Dr. Mahmoud Farouk Sabra Abd-Allah (3)}

\begin{abstract}
:
The current research aim at the study aimed at designing a rehabilitant program to use exercises and laser with the Table Tennis players injured with strained ligaments of the wrist joint and studying its effect on (degree of pain, strength of the muscles of the joint, and range of motion of the joint). The researcher used the experimental method by applying the (before and after) measurements on one experimental group which is enough and suitable for the aim of the research. The research community represents Athletics women in Tennis players in Assiut governorate, season (2015-2016). The research sample was chosen in an intentional method. It consists of 8 players from the professional and premier league (A) in Assiut governorate, aged between 18- 30 years old and they are injured by strained Ligaments of wrist joint needed to be placed in a cast for about 30- 45 days. The researcher used a goniometry for measuring wrist range of motion, a dynamometer for measuring the muscles strength of the target muscles group of the wrist, Visual Analog scale for measuring degree of pain. Results indicate There is a statically positive improvement in the pain degree, motion range, muscles strength of the wrist in the positions of (extraction, extension, retraction, rounding) of the research sample. Also all the improvement percent in the variables are near to the other good hand.
\end{abstract}

Key words: Wrist Joint affected with Ligaments Strain

\section{Background and Problem:}

One of the most common sports injuries in sports stadiums is wrist joint torn, especially players of: hand ball, basketball, Table Tennis, Wrestling, gymnastics, fencing, and football goal keeper. (11-203:209)

Ruptured in ligaments of wrist joint happened when the sports person tries to protect himself from falling down by pushing his arms down, and all his weight is on his hands while the hands are hyper extended and the elbows are stretched and stiff. Moreover, it is because the hand is bent to the back and that result to a direct pain over the wrist joint or an absence of a specific pain point, as a result of the ligament segmentation or the articular capsule, with some inflammations happened at the first hours of injury, it increased according to the injury strength. The movement is limited with a feeling of weakness in the forearm, difficulty in getting things, and instability of the joint, because of the effects on the ligaments that organize the lower ends of the bones of the arm, the radial or ulnar bone, or the eight ligament bones of the wrist. Most kinds of rupture happen at the middle of the ligament. One of the side effects when it is wrong treated, its effect on the function of the wrist especially that controls the rotation movement of the radius and ulnar below the forearm. Men are more infected with wrist strain than women, because men involve in aggressive sports more than women and neglecting good treatment of stain could lead to a surgery.(3-132:133), (14152:153), (39-210:213).

Rehabilitative exercises are those movements made to regains the function of the wrist in a short time. Those exercises are done to improve the muscular performance of the body and strengthen the muscles, bones, joints, and ligaments to reach a high level of physical activity. (13-20), (32-263).

(r) Assistant Professor of Sport Injuries and Physical Rehabilitation, Sports Health Sciences Dept Faculty of Physical Education - Assiut University. 
Besides exercises laser can be used as a kind of electric motivation. It is consider the most modern technology in the field of medical electricity. It has safe and positive physiological effect. It increases the ability to build, multiply the cells and its vividness. It width the vascular and increases blood circulation by heating the issues it exposes through the process of ionizing the molecules. Also, Laser stimulates the immune system of the body by increasing the white blood cells. It contributes in decreasing tumor, edema, and pain. (9-113) (19-139) (23- 41:42)

Moreover, using laser has a positive effect on the treatment of joint pains as it analgesic pain so it increases the ability of the patient to move the joint. (28-24)

The researcher during their work in the fitness and health center in the faculty of Physical Education, Assiut University, and the frequent coming of the Tennis players on the center from different clubs in Assiut governorate, he noticed that there are many players suffer from injury of strained ligaments of wrist joint because of falling on the ground, or while passing or hitting the ball that's needed to and requires repeated rotation movements of the forearm "Pronation, Supination", or Exegesis and stress on ligaments of joint as a result of pressure of training and competitions.

So, as the researcher read and search on the different studies related to their topic, they found that there is not any study deals with the effect of the rehabilitative exercises with laser in rehabilitant of this injury, this impressed them to do this study.

\section{Aim of the study:}

The study aimed at designing a rehabilitant program to use exercises and laser with ligaments of wrist joint injured with strained for the Table Tennis players and studying its effect on (degree of pain, strength of the muscles of the joint, and range of motion of the joint).

\section{Research Procedures:}

Research Methodology:

The researcher used the experimental method by applying the (before and after) measurements on one experimental group which is enough and suitable for the aim of the research.

\section{Research community and sample:}

The research community represents men Table Tennis players in Assiut governorate, season (2015-2016). The research sample was chosen in an intentional method. It consists of 8 players from the first class and professional premier (A) in Assiut governorate, aged between 18- 30 years old and they are injured by strained ligament of hand wrist joint needed to be placed in a cast for a about 30 to 45 days. The start date of the program should not exceed 3 days from of day of injury. The player should not subject to any other rehabilitation programs and to completely regulate in the period of rehabilitation prepared in the program.

Table (1)

Characterization of the Research Sample

\begin{tabular}{c|c|c}
\hline No. & The Changes & \multicolumn{1}{c}{ Research Sample (experimental group) } \\
\hline $\mathbf{1}$ & Members of the sample & \multicolumn{1}{c}{8 members } \\
\hline $\mathbf{2}$ & The treatment used & $\begin{array}{l}\text { - Rehabilitation exercises } \\
\text { - Low strength laser with suitable dose from } \\
685 \mathrm{~nm}: 830 \mathrm{~nm}, \text { long wave }\end{array}$ \\
\hline $\mathbf{3}$ & Start date of the program & $1: 3$ days from the day of removing the gypsum \\
\hline
\end{tabular}

Table 1. Clarifies the following:

- Using rehabilitation exercises with the experimental group (research sample). 
- The researcher used low strength laser 685nm: 830nm, long wave using "BTL-5000 Series" $(60 \mathrm{mw} / 685 \mathrm{~nm}, 400 \mathrm{mw} / 830 \mathrm{~nm})$ directly where pain is on the injured joint wrist of the hand.

- The researcher had done their procedures or measurements paying attention to the "height, weight, age, date of beginning the program", and all the before measurement changes (degree of pain, muscles strength, motion range) of hand wrist" as shown on table (2),

Table2. Equality of the people in the sample according to the height, weight, age, date of starting the program and changes degree of pain, muscles strength, and motion range of hand wrist"

\begin{tabular}{|c|c|c|c|c|c|c|}
\hline \multirow{2}{*}{ Variables } & \multirow{2}{*}{ Measurements } & \multirow{2}{*}{$\begin{array}{c}\text { Measure } \\
\text { Unite }\end{array}$} & \multicolumn{2}{|c|}{ Subjects } & \multirow{2}{*}{ contortion } & \multirow{2}{*}{ Function } \\
\hline & & & $\boldsymbol{X}$ & $\pm Z$ & & \\
\hline \multirow{4}{*}{ Description } & Height & $\mathrm{M}$ & 1.76 & 0.067 & 0.638 & In functioned \\
\hline & Weight & $\mathrm{kg}$ & 78.88 & 3.12 & 0.462 & In functioned \\
\hline & Age & Year & 24.73 & 3.35 & 0.591 & In functioned \\
\hline & Program's Date & day & 2.17 & 0.754 & 0.321 & In functioned \\
\hline Pain Degree & Pain Level & $\begin{array}{l}\text { Ability } \\
\text { degree }\end{array}$ & 82 & 5.93 & 0.42 & In functioned \\
\hline \multirow{5}{*}{$\begin{array}{l}\text { Power } \\
\text { Muscles } \\
\text { Changes }\end{array}$} & $\begin{array}{c}\text { Wrist Flexion } \\
\text { Muscles }\end{array}$ & \multirow{5}{*}{$\mathrm{Kg}$} & 2.05 & 0.17 & -0.73 & In functioned \\
\hline & $\begin{array}{l}\text { Wrist Extension } \\
\text { Muscles }\end{array}$ & & 1.75 & 0.23 & 0.39 & In functioned \\
\hline & $\begin{array}{c}\text { Adduction } \\
\text { Muscles } \\
\end{array}$ & & 1.7 & 0.16 & -0.97 & In functioned \\
\hline & Attraction Muscles & & 1.84 & 0.09 & -1.06 & In functioned \\
\hline & $\begin{array}{l}\text { Hand Flexion } \\
\text { Muscles }\end{array}$ & & 6.21 & 0.77 & 0.78 & In functioned \\
\hline \multirow{4}{*}{$\begin{array}{l}\text { Motion Rang } \\
\text { Changes }\end{array}$} & Wrist Flexion & \multirow{4}{*}{$\begin{array}{l}\text { Angle } \\
\text { degree }\end{array}$} & 26 & 3.84 & -0.05 & In functioned \\
\hline & Wrist Extension & & 30.16 & 5.03 & -0.19 & In functioned \\
\hline & Adduction & & 12.66 & 1.75 & -0.44 & In functioned \\
\hline & Attraction & & 9.33 & 1.50 & 0.39 & In functioned \\
\hline
\end{tabular}

Table 2 clarifies the following:

* The average value of the descriptive contortion changes are between the ranges of (-0.638: 0.462$)$, the pain degree change is 0.42 , power muscles changes between the range of (-1.06: 0.78), motion range changes between the ranges of (-0.44: 0.39). These mean that, all the changes range between $( \pm 3)$. That means the equality of the distribution of the research sample and the homogeneity of the people in the changes.

\section{- Data Collecting Tools:}

* Analysis of the scientific literature and previous studies and sports related injuries.

* Personal interviews conducted by the researcher with faculty member's doctors from, Department of Rheumatology and Rehabilitation and Physical Medicine to determine the nature and degree of the injury.

* A questionnaire to consult the expert on qualifying program proposed in terms of the contents of exercises qualification and exposure to a laser beam low-intensity $(685 \mathrm{~nm}$ : $830 \mathrm{~nm}$ ), it is displayed to the experts (included 1) in the fields of health and injuries from faculty of physical education, and the fields of Rheumatology and Rehabilitation and Physical Medicine faculty of Medicine, to be sure of the validity and possibility to be applied on this degree of injury. (Included 7)

* Data collection form for private respondents for each individual injured personally. (Included 2)

* Data collection form for the measurements of muscle strength, range of motion and the degree of pain. (Included 3)

* Electronic Restameter, to measure the height and weight. 
* Electronic Dynamometer, measure the muscles strength of the target muscles group of the wrist applied in the research. (Included 4)

* Goniometer the motion range of the wrist. (Included 5)

* Visual analog scale (V.A.S) for measuring degree of pain. (Included 6)

* A survey conducted during the period from 17/5/2016 until 23/5/2016 on two patients to find the following:

- Evaluating the patient motion level personally.

- Legalization of load for the exercises group under investigation that suites each patient personally.

- Being sure that the tools and equipment are suitable for the samples under investigation.

\section{- The basis for implement of the suggested program:}

1- The exercises are done personally according to case of each patient.

2- The exercises are done gradually according to the pain limit of each patient.

3- The program is divided into three levels, the duration of each level two weeks, and five sessions a week.

4- There are eight laser sessions on the pain each session takes ( $3 \mathrm{~min}: 5 \mathrm{~min}$ ) according to the doctor's recommendations and the injured place is cleaned with alcohol before each session.

5- The duration of the qualified unit is (30 $\mathrm{min}: 45 \mathrm{~min}$ ).

\section{- The content of the suggested qualified program:}

1- the first stage started by applying a group of Isometric exercises (negative- with help) with laser to reduce the pain till we get rid of it by removing edema and inflammation from the area of injury. Also developing the muscles tone and the flexibility of the joints on all of its motion position and in all directions.

2- By the beginning of the second stage we start the performance of a set of Isometric and Isotonic exercises (free- with help), with the completion of the treatment by laser, two sessions on the third week, to develop the muscles tone and the flexibility of the joints on all of its motion position and in all directions.

3- In the third stage we gradually begin applying a set of Isometric, Isotonic, and Isokindic exercises (free-Against Resistance), trying to reach the normal motion range and muscles strength in compare with the other not injured hand.

\section{- The research steps:}

The researcher have done the following:

1- Made the before measurements on the sample under investigation every one alone, according to the date of injury and the time beginning qualifying the patients or the injured from the date $7 / 6 / 2016$ to $8 / 10 / 2016$.

2- Applying the suggested program individually on the injured experimental group (research sample) from date 8/6/2016 to 23/11/2016.

3- Making gradual measurements to determine the progress of each injured and codifying the used loads gradually according to the changes appeared on the physical health status of the research sample.

4- Made the after measurements on the sample under investigation every one alone, according to the time beginning qualifying the injured from the date 22/7/2016 to 24/11/2016.

5- Collecting, sorting and analyzing the data.

\section{- Statistical processors:}

* Arithmetic Mean.

* Standard Deviation.

* Coefficient Sprains. 
* The "T" test.

* The Percentage Rate.

- The Results:

In light of the research problem and achieving its aim the researcher display the results classified as followed:

1- The results of the pain level for the research sample:

Table 3.

Significant differences between the averages of measurements before and after for the experimental group in the light of the pain degree change $(n=8)$

\begin{tabular}{|c|c|c|c|c|c|c|c|c|c|c|c|c|}
\hline Changes & \multicolumn{2}{|c|}{ Before } & \multicolumn{2}{|c|}{ After } & \multirow{2}{*}{ DA } & \multirow{2}{*}{ IP \% } & \multirow{2}{*}{ "T" value } & \multirow{2}{*}{$\mathbf{f}$} & \multicolumn{4}{|c|}{ Measuring the good wrist $n=16$} \\
\hline Pain & $\mathbf{X}$ & $\pm \mathrm{Z}$ & $\mathbf{X}$ & $\pm \mathrm{Z}$ & & & & & $\mathbf{X}$ & $\pm \mathrm{Z}$ & "T" value & f \\
\hline Pain degree & 82 & 5.93 & 8.83 & 4.44 & 73.17 & 89.23 & -2.25 & $\mathbf{f}$ & 0.00 & 0.00 & 0.63 & $\varnothing$ \\
\hline
\end{tabular}

The "T" value $0.05=1.89 \quad \mathrm{DA}=$ Different between Average,

IP = Improvement Percentage, $f=$ function, $\emptyset=$ no function.

It is clear from table 3 the following:

There were statistically significant differences between the before and after mean measurements of the experimental group (research sample) in the pain level for the after measurements, value $(\mathrm{T})$ calculated at 0.05 , the percentage improvement $(89.23 \%)$. And there are not statistically significant differences between the mean measurements of the infected hand and the good hand measurements averages in the pain level, value of $\quad(T)<0.05$.

2- The results of the muscles strength for the research sample:

Table 4.

Significant differences between the averages of measurements before and after for the experimental group in the light of the muscles strength changes of the wrist $(\mathrm{kg})(\mathrm{n}=8)$

\begin{tabular}{|c|c|c|c|c|c|c|c|c|c|c|c|c|}
\hline \multirow{2}{*}{$\begin{array}{c}\text { Changes } \\
\begin{array}{c}\text { Muscles working } \\
\text { on wrist }\end{array} \\
\end{array}$} & \multicolumn{2}{|c|}{ Before } & \multicolumn{2}{|c|}{ After } & \multirow{2}{*}{ DA } & \multirow{2}{*}{ IP \% } & \multirow{2}{*}{$\begin{array}{c}\text { "T" } \\
\text { value }\end{array}$} & \multirow{2}{*}{$\mathbf{f}$} & \multicolumn{4}{|c|}{$\begin{array}{l}\text { Measuring the good wrist } \\
n=16\end{array}$} \\
\hline & $\mathbf{X}$ & $\pm \mathbf{Z}$ & $\mathbf{X}$ & $\pm z$ & & & & & $\mathbf{x}$ & $\pm \mathbf{Z}$ & $\begin{array}{c}\text { "T" } \\
\text { value } \\
\end{array}$ & f \\
\hline Wrist flexion & 2.05 & $\mathbf{0 . 1 7}$ & 3.7 & 0.52 & 1.65 & $44.6 \%$ & 2.47 & $\mathbf{f}$ & 3.01 & 0.76 & $\mathbf{0 . 0 7}$ & $\varnothing$ \\
\hline Wrist extension & 1.75 & 0.23 & 3.07 & 0.46 & 1.32 & $43 \%$ & 3.17 & f & 2.64 & 0.73 & 0.21 & $\varnothing$ \\
\hline Wrist adduction & 1.7 & 0.16 & 2.94 & 0.36 & 1.24 & $42.2 \%$ & 3.88 & $\mathbf{f}$ & 2.33 & 0.60 & 0.008 & $\varnothing$ \\
\hline Wrist attraction & 1.84 & 0.09 & 3.26 & 0.17 & 1.42 & $43.6 \%$ & 1.95 & $\mathbf{f}$ & 2.61 & 0.70 & 0.056 & $\varnothing$ \\
\hline Hand flexion & 6.21 & 0.77 & 31.5 & 2.73 & 25.29 & $80.3 \%$ & 4.61 & $\mathbf{f}$ & 28.5 & 2.42 & 0.09 & $\varnothing$ \\
\hline
\end{tabular}

The "T" value $0.05=1.89 \quad$ DA= Different between Average, $I P=$ Improvement Percentage, $f=$ function, $\emptyset=$ no function.

It is clear from table 4 the following:

There were statistically significant differences between the before and after mean measurements of the experimental group (research sample), value (T) calculated at 0.05 , in variables muscle strength of the muscles working on the wrist for the after measurements, while ranged improvement between $(42.2 \%)$ and $(80.3 \%)$. and there are not statistically significant differences between the mean dimensional measurements of the infected hand and hand measurements averages in these variables, with the value in $(\mathrm{T})<0.05$.

3- The results of the motion range for the research sample: 
Table 5.

Significant differences between the averages of measurements before and after for the experimental group in the light of the motion range changes of the wrist (angle) $(n=8)$

\begin{tabular}{|c|c|c|c|c|c|c|c|c|c|c|c|c|}
\hline Changes & \multicolumn{2}{|c|}{ Before } & \multicolumn{2}{|c|}{ After } & \multirow{2}{*}{ DA } & \multirow{2}{*}{ IP \% } & \multirow{2}{*}{$\begin{array}{c}\text { "T" } \\
\text { value }\end{array}$} & \multirow{2}{*}{$\mathbf{F}$} & \multicolumn{4}{|c|}{$\begin{array}{l}\text { Measuring the good wrist } \\
\qquad n=16\end{array}$} \\
\hline $\begin{array}{l}\text { Range of motion } \\
\text { for wrist }\end{array}$ & $\mathbf{X}$ & $\pm \mathbf{Z}$ & $\mathbf{X}$ & $\pm z$ & & & & & $\mathbf{x}$ & $\pm \mathbf{Z}$ & $\begin{array}{l}\text { "T" } \\
\text { value }\end{array}$ & $\mathbf{f}$ \\
\hline Wrist flexion & 26 & 3.84 & 48.5 & 5.68 & 22.5 & $46.4 \%$ & 2.21 & $\mathbf{F}$ & 46.33 & 6.08 & 0.58 & $\varnothing$ \\
\hline Wrist extension & 30.16 & 5.03 & 52.83 & 5.67 & 22.67 & $42.91 \%$ & 2.04 & $\mathbf{F}$ & 50 & 6.32 & 0.36 & $\varnothing$ \\
\hline Wrist adduction & 12.66 & 1.75 & 22.83 & 2.63 & 10.17 & $44.55 \%$ & 7.98 & $\mathbf{F}$ & 20.58 & 3.32 & 0.21 & $\varnothing$ \\
\hline Wrist attraction & 9.33 & 1.50 & 16.16 & 1.72 & 6.83 & $42.26 \%$ & 3.42 & $\mathbf{F}$ & 14.66 & 1.96 & 0.20 & $\varnothing$ \\
\hline
\end{tabular}

The "T" value 0.05= 1.89 . DA= Different between Average, $\mathrm{IP}=$ Improvement

Percentage, $f=$ function, $\varnothing=$ no function.

It is clear from table 5 the following:

There were statistically significant differences between the before and after mean measurements of the experimental group (research sample), value (T) calculated at 0.05 , in variables muscle strength of the muscles working on the wrist for the after measurements, while ranged improvement between $(42.26 \%)$ and $(46.4 \%)$. There are not statistically significant differences between the mean dimensional measurements of the infected hand and hand measurements averages in these variables, with the value in $\quad(T)<0.05$.

\section{Second: Discussion and Results analyses}

In Tables (3), (4), (5) it is noticed that, there were statistically significant differences between the mean measurements before and after in the experimental group (research sample) in the variables (Pain degree - Muscle Strength - Motion Range) of the wrist, and they were all for the after measurements. The value calculated for all measurements $(\mathrm{T})>$ 0.05 , as all the results reflect the positive improvement of all variables of the after measurements.

The researcher due this positive improvement statistically signifier in the Pain degree $(89.23 \%)$ improvement because of using the Isometric exercises gradually. With directing a low-intensity laser $(685 \mathrm{~nm}: 830 \mathrm{~nm})$ on the pain points around the wrist joint during the first stage and the first week of the second stage. That greatly helped in removing Edema and inflammation in the place of injury and led to gradual decrease of the pain and even getting rid of it completely.

This is consistent with what it is referred to in American Pain Foundation (2006), Ryad ,Abdel-Rahim (2001), Ryad (2000), that exercise is the common way in rehabilitation programs to relief the pain, they don't only maintain your health, but also help to reduce the pain, especially the Joints pain, and it helps to control the pain of Joints, swelling as a result of Joints inflammation. (42-28), (7-96), (5-79)

Also this is consistent with what Pinar. et,al (2005) concluded, and with what Carolyn, Lynn (2007) confirmed that the static, dynamic rehabilitative exercises and lasers help on rapid improvement to relief the pain and a great improvement on the ability of the hand to catch.(35), (22-118)

Moreover, this research results agree with the study results of Ibrahim (10- 1996), Ouda (18-2009), Ekim (24-2007), that rehabilitative exercise program, natural treatment with laser have effective role in improving the level of pain.

Mengoshoel \& Fore (2006), refer that, regular physical exercise that is practiced without fatigue and pain lead to the minimization of pain resulting from injuries. (33-269)

The researcher comment on the positive improvement in most muscles' variables of the working muscles group of the wrist, also the high percent improvement of these variables of average between (42.2\% muscles adduction the wrist: $80.3 \%$ muscles of Hand flexion). 
These improvements are related to the exercises used in the suggested qualified program and the stable, moved, Isokinetic exercises it included and done (negatively, positively, with help, free, or against resistance) gradually according to each stage, the ability of every case and the level of progress in each case. In addition to, using a different set of Resistors (Medical Corps - Dumb bells - Bands - sand bags or iron filings -fingers Bands - Balls - Multi Gym), to develop muscle strength with Isokinetic training.

Ryad \& Abdel Rahim (7-2001), agree with all the above mentioned that, applying stable exercises then gradually use exercises with help, then free, then against resistance are of great importance in the improvement and development of muscular work, and this gradually increased resistance rise to reach the best possible level without any side effects.

Moreover, Ibrahim (2-2009), Amr (18-2009), Marliene, Jack, and John (30-2001), their studies agree that the program has a positive effect on the muscle strength of the muscles of the joints under investigation. It led to the joints relief with a great percent to its normal position before the injury.

Zaher (2004) declares that the qualifying exercises improve the strength without moving the joints or the muscles. This method is very important in the treatment after the injury or within it. (12-60)

Although, the researcher chose according to the experts (5) the tests for measuring the muscles strength of the working group muscles of the wrist, in all angels of the joint but they agree that fist strength test is one of the honest tests of human fist strength.

Helmy (2-2009), Mansour (8-2005), Hamad (15-2002) agree that there is a great improvement on the grip strength because of the big varieties of exercises within the qualified programs of the hand.

The researcher clarify that the great positive effect in all the variables of the motion range of the wrist and the high percent of improvement of these variables range between (42.26\% wrist extension: $46.4 \%$ wrist fist) is related to the use of different kinds of exercises besides using the laser to alert the cells and get rid of edema, inflammation and relief pain. All these things help applying all different types of exercises and increase the motion range gradually till reaching to the normal level. Furthermore, applying the exercises especially those (negative and with help) in the first stages of the program help in developing the flexibility of the muscles till reaching the normal motion moving in all directions of the joint.

Ouda (18-2009), Bjordal, et,al (21-2008), Ekim (24-2007), Ibrahim (10-1996), they all agree the importance of the qualified exercises side by side using the laser, help relieving the pain and retrieve the flexibility of the joint. Abdel-Hamid (2005), Carolyn, Lynn (2007), also agree with what is mentioned above. (13-20), (22-102). Mary Beth (31-1995), Maria et al (29-1995), James et al (26-1996), all agree the important of these exercises which fed the joint cartilage and made tissues collagen that help in the flexibility of the joints. William \& Coctill (27-2000), Jean (27-2002) their studies agree with above mentioned.

The researcher found that there is no statistically significant differences between the mean of the wrist infected of the experimental group (research sample) and average measurements of the good wrist in research variables (the Pain degree - muscle strength Motion Range) to the program of exercises and the use of lasers low-intensity, during the regularity of all the injured players research sample at the rehabilitative sessions. The development of range of motion, prolonging and muscle strength in all corners of the muscular job available in all the conditions of the movement of the joint, according to the limits of pain, the degree of progress depending on each case privately and in line with the qualifying stage and their aims.

Moreover, Low-intensity laser especially in the first stage and the first week of the second stage works to increase the ability of cells to construction and reproduction and stimulate body's immune system by increasing the number of white blood cells by heating the 
place of infection that leads to revascularization and increased activity of the circulatory which contributes effectively to alert the vital cells and increase metabolism, as it works so on reduce the incidence of edema or swelling and remove the inflammation and thus relieve pain.

The researcher added, using some different exercises (negative- with help- freeagainst resistance) depending on the qualifying stage and the level of progress of each case, using a number of gradual resistances, and the research sample uses a number of similar exercises using (Medical balls - Dumb bells - Bands - sand bags or iron filings -fingers Bands - Balls - Multi Gym), has a great effect on healing the motion range of the wrist and the muscles strength compared with the other good hand.

Bakry \&Ghamry (2005) found that healing with systemized motion is one of the basic natural ways in the field of a complete treatment; the healing process depends on the motion qualifying of different exercises. (17-78)

Stephen et al (2000) mentioned that one of the main aims of the qualified exercises is limiting pain, increasing the flexibility of the muscles of the pain area, the motion range of the joints, then the injured part returns back to its normal condition. (36-444)

Al- khatieb et al (2000), mentioned that the angels of the muscles help building muscles. (20-25)

Abdel-Fattah (1998), Kesraa (1998) say that muscles strength work out lead to breadth of capillaries that increase the blood pressure artery, mitochondria, and strength the bone system and the body in general.(1-97), (4-21)

Ryad and Abdel-Rahim (2001), point that it is important to do the exercises regularly until they achieve their aim or goal. (7-154)

The Rehabilitation Center (40-41, 2009) clarifies that the low- intensive laser can be used with the cases of rupture or strain muscles or ligaments articular and can also be used with cases of pain wrist and the hand. William (2006), mentioned that the exercises made for injured joints should be made especially the bending and tide movements, stability work out, rounding exercises to the limit the patient fell the pain. (35-38)

Also Bakry (16-2000), and Olivier (34-2008) agree with the above mentioned, that the scientific qualified motion program is important for the muscles strength, relief pain and improve the function of injured place.

\section{- Conclusions:}

* There is a statically positive improvement in the pain degree, motion range, muscles strength of the wrist in the positions of (extraction, extension, retraction, rounding) of the research sample.

* Diversity in the rehabilitative exercises depending on the status of each infected with one of the factors that increase the effectiveness of rehabilitative exercises for Wrist Joint affected with Ligaments Strain

* The use of low-intensity laser has had a significant positive impact in removing inflammation and pain relief, which allowed for gradual implementation of the program exercises.

* All the improvement percent in the variables are near to the other good hand.

\section{-Recommendations:}

1- It is important for the men table tennis players who have a strain ligaments of wrist joint to make this qualified suggested program and concentrate on using rehabilitation exercises with Low suitable dose of laser for quick healing. 
2- It is important to use many methods while dealing with the suggested exercises (with helpfree- against resistant) depending on the case condition and the qualifying stage.

3- The important of using muscles work exercises (isometric, isotonic, Isokinetic) during qualifying the injured and depending on the qualifying stage and the progress condition of each case.

4- Applying this qualified suggested program with players in different sports and have the same injury.

\section{References:}

\section{First: Arabic References}

1- Aboel-Ela Abdel-Fatah: Training Science and Physiology Basises, Dar El-Fekr Alaraby, Cairo.1998.

2- Ahmed Helmy Saleh: "Influence of Rehabilitation Training Program on wrist without Sergey", M.A thesis, Faculty of Physical Education, Tanta University, 2009.

3- Ahmed Fayez El-Namas: "Sports Injury and Treatment", Cairo, 1996.

4- Ahmed Kesraa: "Encyclopedia of Training Science", Cairo, 1998.

5- Osama Mostafa Riad: "Sport medicine and Rehabilitation", Cairo, 2000.

6- Osama Mostafa Riad, Emam El-Nagmy: "Sport medicine and Rehabilitation", Cairo ,2000.

7- Osama Mostafa Riad, Nahed Ahmed AbdElRahim: Megerment and Rehabilitation movment for descomfert, Dar El-Fekr Alaraby, Cairo. 2001.

8- Ehab Ahmed Metwally: "Rehabilitation Program for Arm Muscles after Nerve Sergey, M.A thesis, Faculty of Physical Education, Tanta University, 2005.

9- Poul Shoshar: Translated by Hala Murad, "Pain",Cairo, Dar Al-Mustaqbal, 1992.

10- Khalel Ibrahim Khalel: "Effect of Rehabilitation Program, Laser and Ultrasonic on Pain for the femur Joint Master, Faculty of Physical Education, Port said, Sues Qanal University, 1996.

11- Samiaa Khalel Mohammed: "Sport Injuries and Rehab. Methods, Cairo, 2008.

12- Abdel-Rahman Abdel-Hamed Zaher: "Encyclopedia of Sport Injuries and Emergency First Aids", Cairo, 2004.

13- Frarag Abdel-Hamed Tawfiq: "An Important of Physical Exercise for Treatment Body Deformation, Cairo, 2005.

14- Magdy Al-Hosiny Elewa: "Sport Injuries Between Prevent and Treatment Zaqaziq, 1997.

15- Mohamed Abdel-Aziz Hamad: "Effect of Treatment Exercise on Some of Physiological, Physical relation with wrist Hand Inflammation", M.A thesis, Faculty of Physical Education, Helwan University, 2002.

16- Mohamed Qadry Bakry: "Sport Injuries and New Qualifications, Publication Book Center, Cairo, 2000.

17- Mohamed Qadry Bakry and Seham Al- Ghamry: "Sport Injuries and Physical Qualification, Dar Al- Manar, Cairo, 2005.

18- Mostafa Oda Amro: "Effect of Treatment Exercise with Laser on Elbow Joint Efficiency ", M.A thesis, Faculty of Physical Education, Helwan University, 2009.

19- Nader Mohamed Abdel-Aziz: "Using Laser on Treatment of Physical Therapy", M.A thesis, Faculty of Physical Therapy, Cairo University, 1999.

20- Nariman El-Khatib, Abdel-Aziz Al-Nemr, Amro El-Sokary: "Muscular Stretching", Book Publication Center, 2000.

\section{Second: Foreign References}

21- Bjordal, et, al: "A systematic review procedural assessments and meta analysis of low level laser therapy in lateral elbow tendinopathy (tennis elbow) bc"- musculoskeletal disorders, 2008.

22- Carolyn Kisner, Lynn Allen Colby: Therapeutic exercise, Foundations and techniques, 5th ed, F. A. Davis Company Philadelphia, 2007.

23- David Bawsher, Peter Ewells, Vitoial Frampton: Pain, seeonel. ed, pp, 41-42, 1994. 
24- Ekim A, Armagan O, Tascioglu F, Oner C, Colak M: "Effect of low level laser therapy in rheumatoid arthritis patients with carpal tunnel syndrome", Osmangazi University, Department of Physical Therapy and Rehabilitation, Eskisehir, Turkey, 2007 June, 16;137 (23-24):347-52.

25- Filip M. Vanho enacker, Mario Maas, Jan L. Gielen: Imaging of Orthopedic Sports Injuries, Springer, 2007.

26- James, Chappuis, Md \& al: " The super six strengtheners for Golfers", J. sports Med. Vol. 24. No. 4, April.pp.87.88,publication of the Megraw. Hill companies, 1996.

27- Jean Dubois: les principles de 1, entrainment sport if, Bordeaux Universited, Bordeux, France, 2002.

28- King, C,E,clell, J,A,Knowles,G,J: Effect of hel win neon iaseraurical therapy onex permintal pain. Phys therapy, vol, 70, 1990, pp 24.30.

29- Maria Zuluagu et al: " sports physiotherapy Applied science \& practice", Edinburg. churchill living stone, 1995.

30- Marlene F, Jack C, \& John D: physical Therapy Is Effective for patients with Ostear thirties of the Journal of Rheumatology. Vol,28:156,64,USA, 2001.

31- Marybeth Brown, ph D, Pt: " The older Athlete with Tennis elbow", J. sports Med. Vol14, No.1, January. pp. 267-274, washing University, USA, 1995.

32- McMahon, Patrick J: Current Diagnosis\& Treatment in Sport Medicine, 1st Edition, McGraw, Hill, 2007.

33- Mengoshoel, A, M: Vollested, N, k; ZForre, o, Pain and fatigue induced by exercise in fibromyalgia patients and sedentary healthy subjects clin Exp Rheumatol (BIBLIOGRAPHIC CITATION): CLIP- JUL-AUG; 13(4), P.P. 477-482, 2006.

34- Olivier N: “ Lepretre ACaby I. Dupuis MA Prieur F Ann Readapt Med phus, 2008, May.

35- Pinar L, Enhos A, Ada: Can we use nerve gliding exercises in women with carpal tunnel syndrome? Gazi University Faculty of Medicine, Department of Physiology, BesevlerAnkara, Turkey, 2005.

36- Stephen A. Paget et. al: Manual of Rheumatology and Outpatient Orthopedic Disorders, Diagnosis and Therapy, Fourth Edition, Lippincott Williams \& Williams, Philadelphia, USA, 2000.

37- William A. \& Coctill D.: Physiolog4 of sport and Exercise, Champaign, U.S.A, 2000.

38- William nlevine: the stiff elbow, American academy of orthopedic surgeons, 2006.

\section{Third: Web Sites}

39- http://www.al-batal.com/main/games-and-other-sports/

40- http://www.taaheal.com/?page_id=208

41- http://www.taaheal.com/?page_id=213

42- www.painfoundation.org//--Treatment Options: A Guide for People Living with Pain, American Pain Foundation, 2006. 